\title{
Clinical risk factor assessment had better discriminative ability than bone mineral density in identifying subjects with vertebral fracture
}

\author{
S. W. Y. Tsang • C. H. Bow $\cdot$ E. Y. W. Chu • \\ S. C. Yeung • C. C. Soong • A. W. C. Kung
}

Received: 6 October 2009 / Accepted: 30 March 2010/Published online: 26 May 2010

(C) The Author(s) 2010. This article is published with open access at Springerlink.com

\begin{abstract}
Summary This study evaluated the characteristics of patients with vertebral fractures and examined the discriminative ability of clinical risk factors. The findings provide further insights into possible development of a simple, cost-effective scheme for fracture risk assessment using clinical risk factors to identify high-risk patients for further evaluation.

Introduction Vertebral fractures are the most common complication of osteoporosis. The aim of this study was to evaluate the characteristics of patients with vertebral fractures and to determine the discriminative ability of bone mineral density (BMD) and other clinical risk factors.

Methods Postmenopausal Southern Chinese women $(2,178)$ enrolled in the Hong Kong Osteoporosis Study since 1995 were prospectively followed up for fracture outcome. Subjects $(1,372)$ with lateral spine radiographs were included in this study. Baseline demographic, BMD, and clinical risk factor information were obtained from a structured questionnaire. Results Subjects (299; 22\%) had prevalent vertebral fractures. The prevalence of vertebral fractures increased with increasing age, number of clinical risk factors, and decreasing BMD. The odds of having a prevalent vertebral fracture per SD reduction in BMD after adjustment for age in Hong Kong Southern Chinese postmenopausal women was 1.5 for the lumbar spine and femoral neck. Analysis of the receiver operating characteristic curve revealed that bone mineral apparent density did not enhance fracture risk prediction. Subjects with $\geq 4$ clinical risk factors had 2.3-fold higher odds
\end{abstract}

S. W. Y. Tsang $\cdot$ C. H. Bow $\cdot$ E. Y. W. Chu $\cdot$ S. C. Yeung $\cdot$

C. C. Soong $\cdot$ A. W. C. Kung $(\square)$

Department of Medicine, The University of Hong Kong,

Queen Mary Hospital,

Pokfulam Road,

Hong Kong, China

e-mail: awckung@hku.hk of having a prevalent vertebral fracture while subjects with $\geq 4$ clinical risk factors plus a low BMD (i.e., femoral neck Tscore $<-2.5$ ) had 2.6-fold. Addition of BMD to clinical risk factors did not enhance the discriminative ability to identify subjects with vertebral fracture.

Conclusions Based on these findings, we recommend that screening efforts should focus on older postmenopausal women with multiple risk factors to identify women who are likely to have a prevalent vertebral fracture.

Keywords Ethnicity · Osteoporosis · Prevalence ·

Southern Chinese $\cdot$ Vertebral fracture

\section{Introduction}

Osteoporosis is a disease associated with decreased bone mass and bone strength and leads to increased fracture risk. Due to its high prevalence worldwide [1], osteoporosis has become a major public health concern. The epidemiology of hip fractures has been intensively studied over the past few decades because of its expensive treatment cost and adverse outcomes. Although hip fractures are less prevalent in Asians [2], vertebral fractures are as frequent in Asian as in Caucasian women [3-5]. Indeed, vertebral fractures are the most common complication of osteoporosis, accounting for nearly $50 \%$ of all osteoporotic fractures [6]. Besides physical deformity, vertebral fracture is associated with reduced mobility and quality of life $[7,8]$, and increased mortality $[9,10]$. Previous studies have shown that vertebral fracture often occurs earlier than hip fractures in disease progression and that vertebral fracture is associated with an increased risk of both future vertebral and nonvertebral fractures [11-14]. Therefore, characterizing the prevalence of vertebral deformities and associated 
clinical risk factors would help physicians and policymakers to determine the appropriate amount of emphasis to be placed on diagnosis and prevention of osteoporosis.

Although vertebral fractures are important as an independent risk factor for further fracture, they are not easy to diagnose as it has been estimated that only $30 \%$ of vertebral fractures come to medical attention [15]. Additionally, prevalence of vertebral fractures tends to vary across ethnic groups and geographic regions [6]. For example, studies in Europe have shown that the prevalence of vertebral fractures was higher in the UK [15] and Denmark [16] and lower in Finland [17]. On the contrary, in instances in which comparable methods and definitions have been used in studies, the prevalence of morphometric or radiographic vertebral fractures has been more similar across regions $[5,18,19]$. Taken together, compared with hip fractures, the epidemiology of vertebral fractures is less well established, especially in Asia.

In this study, we evaluated the clinical profile in Southern Chinese postmenopausal women with vertebral fracture and examined for clinical risk factors and possible ethnic difference associated with vertebral fracture in this population.

\section{Methods}

\section{Study population}

This is a part of the Hong Kong Osteoporosis Study (HKOS), in which 2,178 community-based postmenopausal women (defined as at least 1 year has passed their last menstrual cycle) who were $\geq 45$ years of age were recruited from health fairs held in various districts in Hong Kong for identification of genetic and environmental risk factors for osteoporosis and fractures [20, 21]. Participants who received anti-osteoporosis treatment and/or postmenopausal hormonal replacement therapy were excluded from analysis. For the present study, 1,372 (63\%) subjects with lateral thoraco-lumbar spine radiographs available for evaluation of vertebral height at the first visit were included in the analysis. The subjects with spine radiographs had similar clinical characteristics with those who did not have radiographs at baseline (data not shown). The study protocol was approved by the Institutional Review Board of the University of Hong Kong and Hospital Authority Hong Kong West Clustered Hospitals, and informed consent was obtained from all participants according to the Declaration of Helsinki.

Anthropometrical and other measurements

Baseline demographic data and clinical risk factors for osteoporosis such as anthropometric measurements, socioeconomic status, education level, low-trauma fracture history after the age of 45 years (both personal and family), history of fall, medical history (including current medication, prior prescription of glucocorticoid and/or hormonal therapy, history of thyroid or parathyroid disease, and gastric or intestinal surgery), and reproductive history were obtained at first visit. Additionally, information on lifestyle habits including smoking and alcohol consumption were also obtained at baseline. Dietary intake of calcium and isoflavone was determined using a semiquantitative food frequency questionnaire. These data were collected from interviews conducted by a trained research assistant using a structured questionnaire.

\section{BMD measurements}

Bone mineral density (BMD) of the L1 to L4 lumbar spine, femoral neck, and total hip were determined using dual-energy X-ray absortiometry (QDR-4500/DELPHI-W, Hologic Inc., Bedford, MA, USA) and by licensed technicians who were accredited by the International Society for Clinical Densitometry. The in vivo precision of the machine in postmenopausal women is $1.2 \%, 1.5 \%$, and $1.8 \%$ at the lumbar spine, femoral neck, and total hip, respectively. The peak young mean \pm SD BMD value used to calculate T-scores for spine, femoral neck, and total hip, obtained from the local Southern Chinese normative database [20], are $1.02 \pm 0.11$, $0.77 \pm 0.09$, and $0.86 \pm 0.10 \mathrm{~g} / \mathrm{cm}^{2}$, respectively.

\section{Vertebral morphometry}

To compare the prevalence and risk factors for vertebral fractures to US white and black women, thoracic and lumbar spine lateral radiographs were taken according to the quantitative procedures described by Black et al. [22]. Briefly, the heights of each vertebra (i.e., anterior (Ha), middle $(\mathrm{Hm})$, and posterior $(\mathrm{Hp}))$ were measured by placement of six points using a cursor and backlit digitizing board. Vertebral morphometric fractures were defined using ratios of vertebral height: the $\mathrm{Ha} / \mathrm{Hp}$ (wedge) ratio, the $\mathrm{Hm} / \mathrm{Hp}$ ratio, and the ratio of posterior heights of adjacent vertebrae $\mathrm{Hpi} / \mathrm{Hp}_{i+1}$ and $\mathrm{Hpi} / \mathrm{Hp}_{i-1}$ (crush). A vertebral body is considered fractured when at least one of its ratios falls below 3 SDs from normative mean values.

\section{Statistical analyses}

The baseline characteristics of Southern Chinese postmenopausal women who had a vertebral fracture were compared with women who did not have a vertebral fracture using $t$ tests for continuous variables and $\chi^{2}$ tests for categorical variables. Logistic regression models were applied to determine the odds ratios (OR) of vertebral fracture and the $95 \%$ CI for each SD decrease in BMD, 
Table 1 Baseline characteristics of postmenopausal women with and without prevalent vertebral fracture $(n=1,372)$

\begin{tabular}{|c|c|c|}
\hline & No vertebral fracture $(n=1,073)$ & Vertebral fracture $(n=299)$ \\
\hline Age $($ mean $\pm \mathrm{SD})$ (year) & $59.8 \pm 7.7$ & $66 \pm 10.1^{*}$ \\
\hline Weight (mean $\pm \mathrm{SD})(\mathrm{kg})$ & $55.3 \pm 9.91$ & $55.4 \pm 10.0$ \\
\hline Height $($ mean $\pm \mathrm{SD})(\mathrm{cm})$ & $153.6 \pm 0.06$ & $151.2 \pm 0.06^{* *}$ \\
\hline Body mass index $($ mean $\pm \mathrm{SD})\left(\mathrm{kg} / \mathrm{m}^{2}\right)$ & $23.1 \pm 3.4$ & $24.2 \pm 3.9^{*}$ \\
\hline Age at menarche (mean $\pm \mathrm{SD}$ ) (year) & $13.9 \pm 2.0$ & $14.7 \pm 2.2^{*}$ \\
\hline Age at menopause (mean $\pm \mathrm{SD}$ ) (year) & $49.5 \pm 3.9$ & $49.7 \pm 4.3$ \\
\hline Years since menopause (mean $\pm \mathrm{SD}$ ) (year) & $11.1 \pm 8.3$ & $17.3 \pm 10.4^{* *}$ \\
\hline Dietary calcium intake (mean $\pm \mathrm{SD})(\mathrm{mg} /$ day $)$ & $681.1 \pm 273.6$ & $652.7 \pm 279.5$ \\
\hline Dietary isoflavone intake $($ mean $\pm \mathrm{SD})(\mathrm{mg} /$ day $)$ & $25.4 \pm 28.3$ & $21.4 \pm 25.3$ \\
\hline Age $\geq 65$ years & $283(26.4 \%)$ & $163(54.5 \%)^{* *}$ \\
\hline $\mathrm{BMI}<19$ & $26(2.4 \%)$ & $11(3.7 \%)$ \\
\hline Age at menarche $>14$ years & $549(51.2 \%)$ & $196(65.6 \%)^{* *}$ \\
\hline Years since menopause $>5$ years & $673(62.7 \%)$ & $234(78.3 \%)^{* *}$ \\
\hline Dietary calcium intake $<400 \mathrm{mg} /$ day & $159(14.8 \%)$ & $53(17.7 \%)$ \\
\hline Dietary isoflavone intake $<9.6 \mathrm{mg} /$ day & $350(32.7 \%)$ & $107(35.8 \%)$ \\
\hline Bilateral-oophorectomy & $64(6.0 \%)$ & $17(5.7 \%)$ \\
\hline Current smoker or drinker & $46(4.3 \%)$ & $22(7.4 \%)^{*}$ \\
\hline Steroid use & $5(0.5 \%)$ & $1(0.3 \%)$ \\
\hline Previous history of taking contraceptive pills & $407(37.9 \%)$ & $84(28.1 \%)^{*}$ \\
\hline Previous history of low back pain & $568(52.9 \%)$ & $175(58.7 \%)$ \\
\hline Previous history of thyroid disease & $54(5.0 \%)$ & $16(5.4 \%)$ \\
\hline Previous history of fracture after age of 45 years $^{\mathrm{a}}$ & $91(8.5 \%)$ & $79(26.4 \%)^{* *}$ \\
\hline Previous history of clinical spine fracture (self-reported) & $0(0 \%)$ & $32(10.7 \%)^{* *}$ \\
\hline History of maternal fracture after age of 45 years & $183(17.1 \%)$ & $29(9.7 \%)^{* *}$ \\
\hline$\geq 1$ fall in 12 months & $168(15.7 \%)$ & $64(21.4 \%)^{* *}$ \\
\hline Walking $<30 \mathrm{~min} /$ day & $138(12.9 \%)$ & $43(14.4 \%)$ \\
\hline Any one site BMD T-score $\leq-2.5$ & $244(22.7 \%)$ & $130(43.6 \%)^{* *}$ \\
\hline
\end{tabular}

${ }^{*} p<0.05 ; * * p<0.001$

${ }^{\mathrm{a}}$ Excluding clinical spine fracture

Table 2 Comparison of bone mineral density (BMD) between postmenopausal women with and without prevalent vertebral fractures

$t$ test for comparison of mean T-score and ANOVA test for category of T-score

${ }^{*} p<0.05 ; * * p<0.001$

${ }^{a}$ Local Southern Chinese normative database was used for calculation of T-scores

\begin{tabular}{lll}
\hline & No vertebral fracture $(n=1,073)$ & Vertebral fracture $(n=299)$ \\
\hline Lumbar spine $(\mathrm{L} 1-\mathrm{L} 4) \mathrm{T}$ T-score $^{\mathrm{a}}$ & & \\
Mean T-score $(95 \% \mathrm{CI})$ & $-1.34(-1.40,-1.27)$ & $-1.75(-1.89,-1.61) * *$ \\
T-score $>-1$ & $37.0 \% *$ & $28.2 \% *$ \\
T-score $<-1$ and $>-2.5$ & $44.1 \% *$ & $40.3 \% *$ \\
T-score $\leq-2.5$ & $17.1 \% *$ & $31.2 \% *$ \\
Total hip T-score & & \\
Mean T-score $(95 \% \mathrm{CI})$ & $-1.05(-1.12,-0.99)$ & $-1.65(-1.79,-1.52) *$ \\
T-score $>-1$ & $47.3 \% *$ & $32.4 \% *$ \\
T-score $<-1$ and $>-2.5$ & $38.8 \% *$ & $38.5 \% *$ \\
T-score $\leq-2.5$ & $11.2 \% *$ & $28.5 \% *$ \\
Femoral neck T-score & & \\
Mean T-score $(95 \% \mathrm{CI})$ & $-1.24(-1.29,-1.18)$ & $-1.75(-1.87,-1.64) * *$ \\
T-score $>-1$ & $39.5 \% *$ & $24.7 \% *$ \\
T-score $<-1$ and $>-2.5$ & $45.8 \% *$ & $46.5 \% *$ \\
T-score $\leq-2.5$ & $13.4 \% *$ & $27.8 \% *$ \\
\hline
\end{tabular}


Table 3 Risk factors for prevalent vertebral fractures based on logistic regression model
${ }^{\mathrm{a}}$ Excluded clinical vertebral fracture

\begin{tabular}{|c|c|c|c|}
\hline & Odds ratio & $95 \% \mathrm{CI}$ & $p$ \\
\hline Age (every 5 years increase) & 1.60 & $1.46-1.76$ & $<0.0001$ \\
\hline Height & 0.86 & $0.83-0.97$ & $<0.0001$ \\
\hline Weight & 0.97 & $0.95-0.98$ & 0.001 \\
\hline Body mass index (treat as continuous variable) & 1.05 & $1.01-1.09$ & 0.006 \\
\hline Menarche age & 1.20 & $1.12-1.30$ & $<0.0001$ \\
\hline Age at menopause & 1.00 & $0.96-1.04$ & 0.94 \\
\hline Years since menopause & 1.08 & $1.06-1.10$ & $<0.0001$ \\
\hline Current smoker/drinker & 1.99 & $1.19-3.33$ & 0.008 \\
\hline Dietary calcium intake $<400 \mathrm{mg} /$ day & 1.46 & $1.03-2.06$ & 0.03 \\
\hline Dietary isoflavone intake $<9.6 \mathrm{mg}$ /day & 1.15 & $0.88-1.50$ & 0.30 \\
\hline Steroid use & 1.41 & $0.16-12.1$ & 0.75 \\
\hline Previous history of taking contraceptive pills & 0.44 & $0.30-0.65$ & $<0.0001$ \\
\hline Previous history of thyroid disease & 1.49 & $0.78-2.85$ & 0.21 \\
\hline Previous history of fracture after age of 45 years $^{\mathrm{a}}$ & 3.80 & $2.77-5.41$ & $<0.0001$ \\
\hline History of maternal fracture after age of 45 years & 1.23 & $0.52-1.88$ & 0.46 \\
\hline 1 or more falls in 12 months & 3.27 & $2.29-4.65$ & $<0.0001$ \\
\hline
\end{tabular}

bone mineral content (BMC), and bone mineral apparent density (BMAD). The relationship between BMD and prevalent vertebral fracture was determined using different models with adjustment for age alone, age and body weight, and a multivariable model of risk factors. Clinical risk factors were included in the multivariable model if they were associated with vertebral fractures $(p \leq 0.1)$. In the multivariable model, we adjusted for age ( $\geq 65$ years), body mass index $\left(\mathrm{BMI}<19 \mathrm{~kg} / \mathrm{m}^{2}\right)$, menarche age ( $>14$ years), years since menopause ( $>5$ years), current smoker or drinker, daily calcium intake $(<400 \mathrm{mg} /$ day $)$, history of fracture (excluding clinical spine fracture), and fall in the last 12 months. To compare the discriminative value of various measurements, we analyzed the areas under receiver operating characteristic (ROC) curves using the $\mathrm{C}$ statistics. Finally, the prevalence of vertebral fractures by age and number of risk factors were determined. ROC curve analysis was conducted using MedCalc package version 9.3 (MedCalc, Mariakerke, Belgium). All statistical analyses were performed using SPSS for Windows version 15.0 statistical software (SPSS, Chicago, IL, USA).

\section{Results}

Two hundred and ninety nine (22\%) subjects were found to have prevalent vertebral fractures. Table 1 summarizes the baseline characteristics of the studied subjects. Compared with women who did not have a prevalent vertebral fracture, women with prevalent vertebral fractures were older, had a later menarche age, had longer time since menopause, and had a higher prevalence of smokers and alcohol drinkers. Furthermore, these women were more likely to fall during the previous 12 months, to fracture after age of 45 years, to report clinical spine fracture, and to have BMD T-score $\leq-2.5$ at anyone skeletal site. Interestingly,

Table 4 Prevalence of one or more vertebral fracture according to the number of clinical risk factors and femoral neck BMD T-score

\begin{tabular}{lcc}
\hline & $\begin{array}{l}\text { Prevalence of vertebral fracture } \\
\text { Number }(\%)(N=1,372)\end{array}$ & Odds ratio (95\% CI) \\
\hline $\begin{array}{l}\text { Number of clinical risk factors } \\
0-1\end{array}$ & $70 / 571(12.3)$ & Reference group \\
$2-3$ & $133 / 596(22.3)$ & $1.13(0.77,1.65)$ \\
$\geq 4$ & $96 / 205(46.8)$ & $2.26(1.36,3.73)$ \\
No. of clinical risk factors+femoral neck BMD T-score & & 0.54 \\
$0-1$ Clinical risk factor+BMD T-score $\geq-2.5$ & $69 / 553(12.5)$ & $0.37(0.05,2.80)$ \\
$0-1$ Clinical risk factor+BMD T-score $<-2.5$ & $1 / 18(5.6)$ & $1.00(0.54,1.87)$ \\
$2-3$ Clinical risk factors+BMD T-score $<-2.5$ & $25 / 96(26.0)$ & $2.64(1.42,4.91)$ \\
$\geq 4$ Clinical risk factors+BMD T-score $<-2.5$ & $56 / 102(54.9)$ & 0.05 \\
\hline
\end{tabular}


Fig. 1 Prevalence (\%) of vertebral fractures by age and the number of risk factors in Hong Kong Southern Chinese postmenopausal women. The number of Southern Chinese women in each group was as follows: $<60, n=665 ; 60-69, n=459$; $70-79, n=204 ; 80+, n=44$. Risk factors included BMI $<19 \mathrm{~kg} /$ $\mathrm{m}^{2}$, menarche age $>14$ years, years since menopause $>5$ years, daily calcium intake $<400 \mathrm{mg}$ / day, current smoker or drinker, history of fall, and fracture history (excluded clinical vertebral fracture)

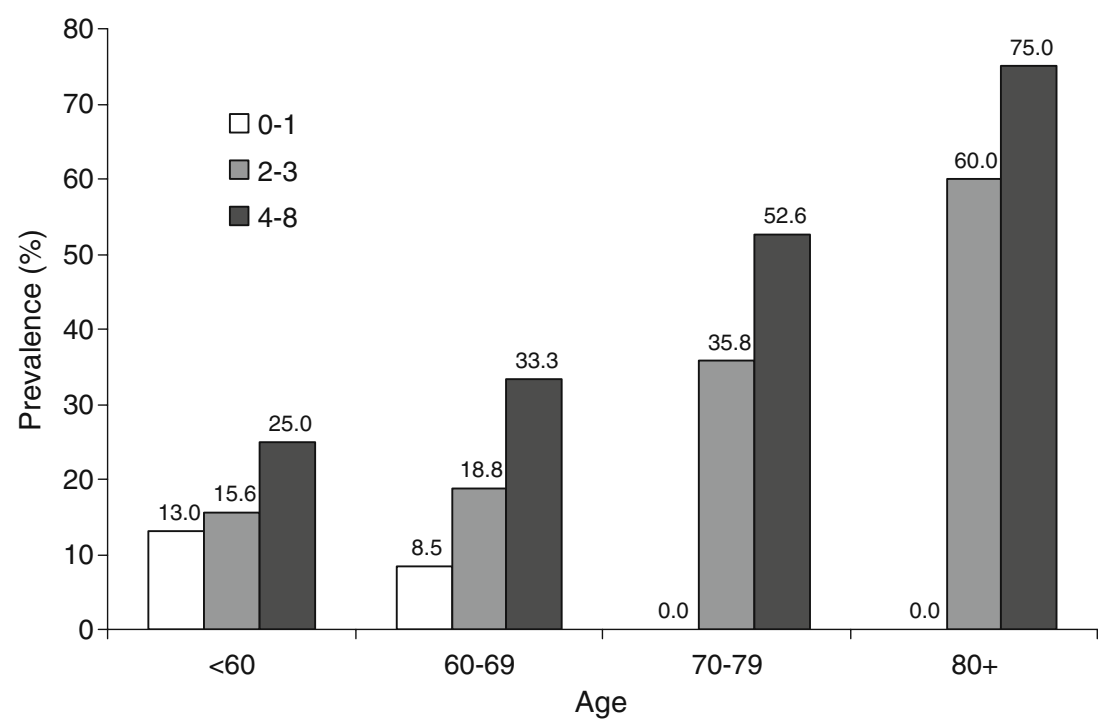

women without vertebral fracture were more likely to have a previous history of taking oral contraceptive pills.

Mean BMD T-score by prevalent vertebral fracture status in Southern Chinese women is shown in Table 2. Subjects with prevalent vertebral fractures had lower BMD values at spine and hip. Using the local Southern Chinese normative database, a significantly higher proportion of women with prevalent vertebral fracture had BMD T-score of -2.5 or less at any one skeletal site compared with those without vertebral fracture. Indeed, the highest prevalence of vertebral fractures was found in women with the lowest tertiles of femoral neck BMD, BMC, and BMAD. Similar results were obtained in the lumbar spine and total hip sites (data not shown).

The clinical risk factors associated with vertebral fractures in logistic regression were age, BMI, menarche age, years since menopause, smoking or drinking, calcium intake, fracture history, and fall in the last 12 months (Table 3). The prevalence of vertebral fracture increased markedly with increasing age and number of clinical risk factors (Table 4 and Fig. 1). For example, the prevalence of vertebral fractures in Southern Chinese women increased sharply with age from 19\% (88/459) between 60 and 69 years to $44 \%$ (89/204) between 70 and 79 years, to $68 \%$ (30/44) for those $\geq 80$ years. Additionally, the highest prevalence of vertebral fractures was found in postmenopausal women with four to eight clinical risk factors at every 10-year age group (Fig. 1). Likewise, the prevalence of vertebral fracture increased significantly with increasing clinical risk factors from $12 \%$ with zero or one risk factor to $47 \%$ with four or more risk factors. Interestingly, adding BMD T-score information did not alter the model significantly (omnibus test $p=0.081$ ), suggesting that the addition of BMD information did not improve the discrimination ability of the model. For example, the odds for vertebral fractures in women with four or more risk factors was 2.26 when compared with women who had the lowest risk (zero to one risk factor) whereas women with a low BMD (Tscore $\leq-2.5$ ) and four or more risk factors had a similar odds of 2.64, when compared with women who had the lowest risk (BMD T-score $>-2.5$ and zero to one risk factor) (Table 4).

In Hong Kong Southern Chinese postmenopausal women, the odds of having a prevalent vertebral fracture per SD reduction in BMD after adjustment for age was $1.51(95 \% \mathrm{CI}$, $1.19,1.90)$ for the lumbar spine and $1.52(1.18,1.98)$ for femoral neck. Likewise, the odds ratio for vertebral fractures for each SD reduction in BMC was $1.49(1.17,1.90)$ for the lumbar spine and $1.51(1.17,1.94)$ for femoral neck. Furthermore, the odds ratio for vertebral fractures for each $\mathrm{SD}$ reduction in BMAD was $1.38(1.07,1.77)$ for femoral neck (Table 5).

Analysis of ROC curves demonstrated that the area under receiver operating characteristic curves (AUCs) for BMD of the lumbar spine and femoral neck were 0.627 and 0.612, respectively, in Southern Chinese postmenopausal women. Additional adjustment for body weight and other risk factors had only a modest effect on the association between BMD and prevalent vertebral fractures in Southern Chinese postmenopausal women. Lastly, we found that femoral neck BMAD did not improve the discrimination ability for prevalence vertebral fracture when compared with BMD.

\section{Discussion}

Prior vertebral fracture is a well-established independent predictor of future osteoporotic fractures, including both vertebral and nonvertebral fractures [24]. Majority of 
Table 5 OR $(95 \% \mathrm{CI})$ for prevalent vertebral fracture for $1 \mathrm{SD}$ decrease in BMD, BMC, or BMAD: age, age and body weight, and multivariable-adjusted models in 1,372 Southern Chinese postmenopausal women

\begin{tabular}{|c|c|c|}
\hline & \multicolumn{2}{|l|}{ Southern Chinese } \\
\hline & OR $(95 \% \mathrm{CI})$ & AUC \\
\hline \multicolumn{3}{|l|}{ Lumbar spine BMD } \\
\hline Age-adjusted & $1.51(1.19,1.90)$ & 0.627 \\
\hline Age and body weight & $1.64(1.26,2.15)$ & 0.635 \\
\hline Multivariate $^{\mathrm{a}}$ & $1.46(1.11,1.93)$ & 0.700 \\
\hline \multicolumn{3}{|l|}{ Lumbar spine BMC } \\
\hline Age-adjusted & $1.49(1.17,1.90)$ & 0.631 \\
\hline Age and body weight & $1.58(1.21,2.05)$ & 0.636 \\
\hline Multivariate $^{\mathrm{a}}$ & $1.40(1.06,1.86)$ & 0.699 \\
\hline \multicolumn{3}{|l|}{ Lumbar spine BMAD } \\
\hline Age-adjusted & $1.39(1.11,1.75)$ & 0.617 \\
\hline Age and body weight & $1.45(1.14,1.86)$ & 0.623 \\
\hline Multivariate $^{\mathrm{a}}$ & $1.39(1.06,1.81)$ & 0.697 \\
\hline \multicolumn{3}{|l|}{ Femoral neck BMD } \\
\hline Age-adjusted & $1.52(1.18,1.98)$ & 0.612 \\
\hline Age and body weight & $1.69(1.26,2.27)$ & 0.628 \\
\hline Multivariate $^{\mathrm{a}}$ & $1.43(1.05,1.95)$ & 0.692 \\
\hline \multicolumn{3}{|l|}{ Femoral neck BMC } \\
\hline Age adjusted & $1.51(1.17,1.94)$ & 0.612 \\
\hline Age and body weight & $1.72(1.28,2.33)$ & 0.623 \\
\hline Multivariate $^{\mathrm{a}}$ & $1.42(1.04,1.96)$ & 0.698 \\
\hline \multicolumn{3}{|l|}{ Femoral neck BMAD } \\
\hline Age-adjusted & $1.38(1.07,1.77)$ & 0.597 \\
\hline Age and body weight & $1.41(1.08,1.85)$ & 0.603 \\
\hline Multivariate $^{\mathrm{a}}$ & $1.29(0.97,1.70)$ & 0.683 \\
\hline
\end{tabular}

${ }^{\text {a }}$ Hong Kong Southern Chinese aged 45 and above: multivariable model includes adjustment for age, BMI, menarche age, years since menopause, smoking or drinking, calcium intake, fracture history, fall in the last 12 months

vertebral fractures are independent of falls and clinically silent, and identification of subjects at risk of vertebral fractures remains a clinical challenge. Using a cohort of community-based population, we observed that the prevalence of vertebral fractures in Southern Chinese women increased exponentially with age from $14 \%$ at ages $<60$ years to $68 \%$ for women age 80 years and older, confirming previous studies [25-29]. Age-specific prevalence of vertebral fractures in postmenopausal women have been previously reported for several ethnic groups including European women aged 50-79 years [27], US white women aged 50 years and above [30], Taiwanese Chinese women aged 40 years and above [19], and mainland Chinese women from Beijing aged 50 and above [18], and the prevalence of vertebral fractures is about $25 \%$ on average in all these groups. In contrast to marked worldwide variations in the prevalence of hip fractures, we demonstrated that the prevalence of vertebral fractures in Hong Kong Southern Chinese postmenopausal women is $22 \%$, which is similar to that of the above-mentioned ethnic groups. One possible reason for the ethnic variations in the prevalence of hip fractures but not in vertebral fractures may be due to the fact that hip fractures often associate with falls, which in turn is associated with low body weight and poor muscle strength, whereas the compression strength of a vertebral body is largely determined by BMD [26]. This study failed to confirm maternal history of fracture as a clinical risk factor. Significantly few women with prevalent vertebral fractures had a positive maternal history of fracture when compared with women without prevalent vertebral fractures. Also, logistic regression did not show a significant association between maternal history of fracture and vertebral fracture prediction $(p=$ $0.46)$. These conflicting results are likely due to missing information on maternal history in a significant proportion of subjects in this observational study.

It is well documented that low BMD, among all clinical risk factors, is the major determinant of vertebral fracture. We previously reported that after the adjustment for age and BMI, the odds of having a vertebral fracture in Southern Chinese women was 2.3 for each $1 \mathrm{SD}$ reduction in spine BMD and 2.1 for femoral neck BMD [20]. Data from the present study revealed that women with prevalent vertebral fractures had significantly lower BMD than those without prevalent vertebral fractures. The odds of having a prevalent vertebral fracture per SD reduction in BMD at the spine and hip after adjustment for age was 1.5 This findings are similar to the US white $(\mathrm{OR}=1.8)$ and black women $(\mathrm{OR}=1.5-1.6)$ [23]. Furthermore, the ability in discriminating prevalence vertebral fracture using BMD at the spine and hip in Southern Chinese women is similar to that of other ethnic groups (AUC $=0.627$ and 0.612 in Southern Chinese, 0.660 and 0.672 in US white, and 0.660 and 0.655 in US black women at the spine and femoral neck respectively) [23]. Likewise, the published Study of Women's Health Across the Nation (SWAN) have demonstrated that BMD was comparable between Asian and Caucasian women after adjustment for body size [31]; therefore, the similarity in the prevalence of vertebral fracture in Southern Chinese and other ethnic groups seems possible. It has been thought that BMAD would provide a more accurate estimate of volumetric BMD because BMAD would compensate for ethnic differences in bone size. However, our results have demonstrated that BMAD did not improve vertebral fracture risk prediction when compared with BMD. The findings suggest that it is not necessary to use BMAD clinically for fracture risk prediction.

Despite the similarities in the discriminating power between the Southern Chinese model and the US white 
and black models using BMD as a discriminator, the clinical risk factors identified were different between the populations, suggesting the importance of population characteristics and lifestyle factors in the pathogenesis of osteoporotic fractures. Interestingly, evaluation of clinical risk factors revealed that the addition of BMD to other factors did not improve the discriminative ability in identifying subjects with vertebral fractures. This observation suggested that clinical risk factors such as age, BMI, menarche age, past history of fracture, and falls are significant contributors to osteoporotic fracture risk over that provided by BMD. The findings are in agreement with previous reports of the World Health Organization algorithms $\left(\right.$ FRAX $\left.^{\circledR}\right)$ for the 10-year absolute risk prediction [32-34]; we found that the prevalence of vertebral fracture was similar between those with or without the addition of BMD T-score to the model. In view of the limited and variable access to radiology investigations in most health care systems in the world, a simple management scheme using clinical risk factors to identify patients for further evaluation would be a more practical approach in the management of osteoporosis.

The present study has several strengths. First, a community-based population was used to investigate the prevalence of radiographic vertebral fractures. Second, identical morphometric assessment methods and definitions were adopted in this study for ease of comparison with data derived from other studies [18, 23, 31]. However, one major limitation of the study is that we did not examine the whole cohort of HKOS study as only 1,372 (63\%) subjects had lateral spine radiographs at the first visit. Therefore, our results may underestimate the true prevalence of vertebral fractures in our population. Also, it is well established that the shape of each vertebral level is unique, for example, vertebrae in the mid thoracic spine and in the thoracolumbar junction are slightly more wedged than other regions of the spine. Using quantitative morphometric approach to diagnose prevalent vertebral fractures may have resulted in misinterpretation of normal variants as mild vertebral deformities. Another drawback of the present study is that our population is likely to have a different SD on BMD, BMC, and BMAD than the Caucasian and black women population in the study of Black et al. [23]. Also, we used different risk factors in the multivariate models from Black's study. Due to the complexity of the differences between the two studies, our study should not be used as a direct comparison to Black's study. Despite these limitations, our results could provide a reference on the Southern Chinese women population. In conclusion, our results demonstrated that the prevalence of vertebral fracture increased exponentially with age and number of clinical risk factors and decreasing BMD. Treatment of women with asymptomatic vertebral fractures has been shown to reduce future hip and vertebral fractures $[35,36]$ and reduce disability [37]; since majority of vertebral fractures are clinically silent, we recommend that caseidentification efforts should focus on older women with multiple risk factors to identify women who are likely to have a prevalent vertebral fracture.

Acknowledgments The authors wish to thank the nursing and technical staff of the Osteoporosis Centre, Department of Medicine, Queen Mary Hospital for their help in carrying out this project. This study was funded by the Bone Health fund of the Hong Kong University Foundation and Osteoporosis Research Fund of the University of Hong Kong.

\section{Conflicts of interest None.}

Open Access This article is distributed under the terms of the Creative Commons Attribution Noncommercial License which permits any noncommercial use, distribution, and reproduction in any medium, provided the original author(s) and source are credited.

\section{References}

1. Cooper C, Campion G, Melton LJ III (1992) Hip fractures in the elderly: a world-wide projection. Osteoporos Int 2:285-289

2. Iki M, Kagamimori S, Kagawa Y et al (2001) Bone mineral density of the spine, hip and distal forearm in representative samples of the Japanese female population: Japanese PopulationBased Osteoporosis (JPOS) Study. Osteoporos Int 12:529-537

3. Kung AW (2004) Epidemiology and diagnostic approaches to vertebral fractures in Asia. J Bone Miner Metab 22:170-175

4. Lau EM, Chan HH, Woo J et al (1996) Normal ranges for vertebral height ratios and prevalence of vertebral fracture in Hong Kong Chinese: a comparison with American Caucasians. J Bone Miner Res 11:1364-1368

5. Ross PD, Fujiwara S, Huang C et al (1995) Vertebral fracture prevalence in women in Hiroshima compared to Caucasians or Japanese in the US. Int J Epidemiol 24:1171-1177

6. Cummings SR, Melton LJ (2002) Epidemiology and outcomes of osteoporotic fractures. Lancet 359:1761-1767

7. Ettinger B, Black DM, Nevitt MC et al (1992) Contribution of vertebral deformities to chronic back pain and disability. The Study of Osteoporotic Fractures Research Group. J Bone Miner Res 7:449-456

8. Nevitt MC, Ettinger B, Black DM et al (1998) The association of radiographically detected vertebral fractures with back pain and function: a prospective study. Ann Intern Med 128:793-800

9. Ensrud KE, Thompson DE, Cauley JA et al (2000) Prevalent vertebral deformities predict mortality and hospitalization in older women with low bone mass. Fracture Intervention Trial Research Group. J Am Geriatr Soc 48:241-249

10. Kado DM, Browner WS, Palermo L et al (1999) Vertebral fractures and mortality in older women: a prospective study. Study of Osteoporotic Fractures Research Group. Arch Intern Med 159:1215-1220

11. Black DM, Arden NK, Palermo L et al (1999) Prevalent vertebral deformities predict hip fractures and new vertebral deformities but not wrist fractures. Study of Osteoporotic Fractures Research Group. J Bone Miner Res 14:821-828 
12. Hasserius R, Karlsson MK, Nilsson BE et al (2003) Prevalent vertebral deformities predict increased mortality and increased fracture rate in both men and women: a 10-year population-based study of 598 individuals from the Swedish cohort in the European Vertebral Osteoporosis Study. Osteoporos Int 14:61-68

13. Klotzbuecher CM, Ross PD, Landsman PB et al (2000) Patients with prior fractures have an increased risk of future fractures: a summary of the literature and statistical synthesis. J Bone Miner Res 15:721-739

14. Lindsay R, Silverman SL, Cooper C et al (2001) Risk of new vertebral fracture in the year following a fracture. JAMA 285:320-323

15. Cooper C, O'Neill T, Silman A (1993) The epidemiology of vertebral fractures. European Vertebral Osteoporosis Study Group. Bone 14(Suppl 1):S89-S97

16. Jensen GF, Christiansen C, Boesen J et al (1982) Epidemiology of postmenopausal spinal and long bone fractures. A unifying approach to postmenopausal osteoporosis. Clin Orthop Relat Res 166:75-81

17. Cooper C, Atkinson EJ, O'Fallon WM et al (1992) Incidence of clinically diagnosed vertebral fractures: a population-based study in Rochester, Minnesota, 1985-1989. J Bone Miner Res 7:221-227

18. Ling X, Cummings SR, Mingwei $Q$ et al (2000) Vertebral fractures in Beijing, China: the Beijing Osteoporosis Project. J Bone Miner Res 15:2019-2025

19. Tsai K, Twu S, Chieng $P$ et al (1996) Prevalence of vertebral fractures in Chinese men and women in urban Taiwanese communities. Calcif Tissue Int 59:249-253

20. Kung AW, Luk KD, Chu LW et al (1999) Quantitative ultrasound and symptomatic vertebral fracture risk in Chinese women. Osteoporos Int 10:456-461

21. Lau HH, Ho AY, Luk KD et al (2002) Estrogen receptor beta gene polymorphisms are associated with higher bone mineral density in premenopausal, but not postmenopausal southern Chinese women. Bone 31:276-281

22. Black DM, Cummings SR, Stone K et al (1991) A new approach to defining normal vertebral dimensions. J Bone Miner Res 6:883-892

23. Cauley JA, Palermo L, Vogt M et al (2008) Prevalent vertebral fractures in black women and white women. J Bone Miner Res 23:1458-1467

24. Delmas PD, Genant HK, Crans GG et al (2003) Severity of prevalent vertebral fractures and the risk of subsequent vertebral and nonvertebral fractures: results from the MORE trial. Bone $33: 522-532$
25. Ismail AA, Cooper C, Felsenberg D et al (1999) Number and type of vertebral deformities: epidemiological characteristics and relation to back pain and height loss. European Vertebral Osteoporosis Study Group. Osteoporos Int 9:206-213

26. Melton LJ III, Kan SH, Frye MA et al (1989) Epidemiology of vertebral fractures in women. Am J Epidemiol 129:1000-1011

27. O'Neill TW, Felsenberg D, Varlow J et al (1996) The prevalence of vertebral deformity in European men and women: the European Vertebral Osteoporosis Study. J Bone Miner Res 11:1010-1018

28. Pluijm SM, Tromp AM, Smit JH et al (2000) Consequences of vertebral deformities in older men and women. J Bone Miner Res 15:1564-1572

29. Spector TD, McCloskey EV, Doyle DV et al (1993) Prevalence of vertebral fracture in women and the relationship with bone density and symptoms: the Chingford Study. J Bone Miner Res 8:817-822

30. Melton LJ III, Lane AW, Cooper C et al (1993) Prevalence and incidence of vertebral deformities. Osteoporos Int 3:113-119

31. Finkelstein JS, Lee ML, Sowers M et al (2002) Ethnic variation in bone density in premenopausal and early perimenopausal women: effects of anthropometric and lifestyle factors. J Clin Endocrinol Metab 87:3057-3067

32. Johansson H, Kanis JA, Oden A et al (2009) BMD, clinical risk factors and their combination for hip fracture prevention. Osteoporos Int 20:1675-1682

33. Kanis JA, Johnell O, Oden A et al (2008) FRAX and the assessment of fracture probability in men and women from the UK. Osteoporos Int 19:385-397

34. Kanis JA, Oden A, Johnell O et al (2007) The use of clinical risk factors enhances the performance of BMD in the prediction of hip and osteoporotic fractures in men and women. Osteoporos Int 18:1033-1046

35. Black DM, Delmas PD, Eastell R et al (2007) Once-yearly zoledronic acid for treatment of postmenopausal osteoporosis. $\mathrm{N}$ Engl J Med 356:1809-1822

36. Harris ST, Watts NB, Genant HK et al (1999) Effects of risedronate treatment on vertebral and nonvertebral fractures in women with postmenopausal osteoporosis: a randomized controlled trial. Vertebral Efficacy With Risedronate Therapy (VERT) Study Group. JAMA 282:1344-1352

37. Nevitt MC, Thompson DE, Black DM et al (2000) Effect of alendronate on limited-activity days and bed-disability days caused by back pain in postmenopausal women with existing vertebral fractures. Fracture Intervention Trial Research Group. Arch Intern Med 160:77-85 